\title{
Determination of Lead in Plastic Food Packaging by Graphite Furnace Atomic Absorption Spectrometry
}

\author{
Tiago Varão Silva ${ }^{a}$, Kelber Miranda ${ }^{a}$, Edilene Cristina Ferreira ${ }^{a}$, Mirian Cristina Santos ${ }^{a}$, \\ José Anchieta Gomes Neto ${ }^{a *}$, and Fernando Barbosa, Jr. ${ }^{\text {b }}$ \\ a UNESP - Univ. Estadual Paulista, Analytical Chemistry Department \\ Rua Prof. Francisco Degni, 55, Quitandinha, 14800-060, Araraquara - SP, Brazil \\ b University of São Paulo, Faculty of Pharmaceutical Sciences of Ribeirão Preto, \\ 14040-903 Ribeirão Preto - SP, Brazil
}

\section{INTRODUCTION}

The global plastics consumption is estimated to reach 297 million tons by 2015 with an expressive fraction being used in food and beverage packaging (1). In this sense, quality control of plastic material for food and beverage represents an increasingly important concern. Besides organic compounds, plastic materials may also hold inorganic species, some of them considered potentially harmful $(2,3)$. The presence of $\mathrm{Cu}, \mathrm{Cr}, \mathrm{Ni}$, and $\mathrm{Pb}$ in polyethylene (4), Sn and Sb in polyvinyl chloride $(5,6), \mathrm{Ag}$ in polypropylene (7), and $\mathrm{Hg}$ in polyethylene, polystyrene, and polyvinyl chloride (8) have been described.

Some toxic metals are frequently added to plastics during the manufacturing process, while others are present as contaminants of raw materials. Lead sulfate and lead stearate are commonly used as additives or stabilizers to protect plastic materials from chemical degradation. Moreover, pigments containing lead chromate are used to color the coating of plastics $(9,10)$. Considering that the presence of lead $(\mathrm{Pb})$, an extremely toxic metal, in plastic material for food and beverage packaging may cause deleterious effects to human health, the development of a simple and fast method for the determination of this element in different types of plastic materials sounds interesting and promising.

Corresponding author.

E-mail: anchieta@iq.unesp.br

(J.A. Gomes Neto)

Tel: +551633019611

\section{ABSTRACT}

Lead sulfate and lead stearate are commonly used as additives or stabilizers to protect plastic material from chemical degradation. Moreover, lead chromate is used in pigments. Considering that the presence of $\mathrm{Pb}$ in plastic material used for food and beverage packaging may cause deleterious effects to the human body, a simple and fast analytical method for $\mathrm{Pb}$ monitoring in plastic food packaging is proposed.

Direct solid sampling highresolution continuum source graphite furnace atomic absorption spectrometry (DSS HR-CS GFAAS) was used as the analytical technique and calibration against aqueous standards was employed. A mixture of $\mathrm{Pd}\left(\mathrm{NO}_{3}\right)_{2}$ and $\mathrm{Mg}\left(\mathrm{NO}_{3}\right)_{2}$ was used as the chemical modifier. The developed method was applied to different plastic containers. For comparison, some samples were also analyzed by inductively coupled plasma mass spectrometry (ICP-MS). The concentration of $\mathrm{Pb}$ in the evaluated samples varied from 16 to $793 \mu \mathrm{g} \mathrm{kg}^{-1}$. A paired $t$-test at a $95 \%$ confidence level showed that the DSS HR-CS GFAAS method provided similar results as those obtained by ICPMS. The proposed method resulted in a characteristic mass of $5.0 \mathrm{pg}$ of $\mathrm{Pb}$ and a limit of detection of $4.9 \mu \mathrm{g} \mathrm{kg}^{-1}$. The relative standard deviation ranged from 2.7 to $18.8 \%$ for the determinations by DSS HR-CS GFAAS and from 2.1 to $13.3 \%$ when using ICP-MS.
Flame or electrothermal atomic absorption spectrometry $(4,9,10)$ inductively coupled plasma optical emission spectrometry (ICP-OES), and inductively coupled plasma mass spectrometry (ICP-MS) (11) are among the main spectroscopic analytical techniques used for elemental determination in plastic materials. These techniques are commonly applied for liquid samples, requiring a previous conversion of the solid material into a solution by acid digestion. Dissolution of plastic polymers by conventional wet decomposition procedures is difficult, unless closed vessels, concentrated acids, high temperatures, and high pressures are involved. Regarding plastic polymer digestion for inorganic analysis, microwave-assisted sample preparation provides several methods based on wet digestion and induced combustion (11). Alternatively, direct solid sampling highresolution continuum source graphite furnace atomic absorption spectrometry (DSS HR-CS GFAAS) seems to be an attractive option for elemental determinations since it does not require previous dissolution of plastic materials. This technique provides low detection limits and offers improved background correction $(12,13)$. Nevertheless, DSS HR-CS GFAAS has been underexplored for the determination of $\mathrm{Pb}$ in plastic materials for packaging food and beverage, only one paper reports the determination of $\mathrm{Pb}$ in plastic material from electroelectronic waste (14).

This study reports the development of a simple and fast DSS HRCS GFAAS method for the determination of $\mathrm{Pb}$ in plastic material 
for food and beverage such as high density polyethylene (HDPE), polystyrene (PS), and polyethylene terephthalate (PET). Accuracy of the proposed method was checked by analyzing two polyethylene (PE) certified reference materials. The method was then applied to the $\mathrm{Pb}$ determination in samples of different plastic polymers, and the results were compared with those obtained by ICP-MS after sample digestion.

\section{EXPERIMENTAL}

\section{Instrumentation}

For the determination of $\mathrm{Pb}$ by direct solid sampling, an Analytik Jena ContrAA 700 high-resolution atomic absorption spectrometer was used (Analytik Jena, Germany). This spectrometer is equipped with a xenon short-arc lamp (XBO 301, $300 \mathrm{~W}$, GLE, Berlin, Germany) as a continuum radiation source, a compact high-resolution monochromator comprising a prism and an Echelle grating with a spectral bandwidth lower than 2 pm per pixel in the far ultraviolet range and a charge-coupled device (CCD) array detector. An automatic microbalance (Sartorius WZ2PW, Göttingen, Germany) with a precision of $0.001 \mathrm{mg}$ was used to weigh the samples directly onto the solid sampling graphite platforms. The sample weight was automatically transmitted to the instrument's computer to calculate the normalized integrated absorbance since it is impossible to always introduce exactly the same sample mass. A previously adjusted pair of tweezers, part of the SSA 600 automatic solid sampling accessory, was used to transfer the solid sampling platforms to the atomizer. Pyrolytic graphite-coated solid sampling tubes without a dosing hole were used. High-purity argon was used as the purge and protective gas.

An Anton Paar Multiwave ${ }^{\circledR}$ microwave oven (Graz, Austria), equipped with a 6-position rotor and 50-mL PFA vessels (minimum filling volume of $6 \mathrm{~mL}$ ), was used to digest the samples for subsequent determination of $\mathrm{Pb}$ by ICP-MS.

An ELAN ${ }^{\circledR}$ DRC ${ }^{\text {TM }}$ II inductively coupled plasma mass spectrometer (PerkinElmer, Inc., Shelton, CT, USA) was used as the comparative technique for $\mathrm{Pb}$ determinations. The operating conditions for the ICP-MS determinations are summarized in Table I.

\section{Reagents, Standards, and Samples}

Deionized water $(18 \mathrm{M} \Omega \cdot \mathrm{cm}$ resistivity), obtained with a Millipore ${ }^{\circledR}$ Rios $5 \AA$ reverse osmosis and a Millipore Milli-Q ${ }^{\circledR}$ Academic deionizer system (Millipore Corporation, Bedford, MA, USA), was used to prepare all solutions. All glassware and polypropylene flasks were washed with Extran ${ }^{\circledR}$ laboratory detergent, soaked in $10 \%(\mathrm{v} / \mathrm{v})$ $\mathrm{HNO}_{3}$ for 24 hours, and rinsed with deionized water prior to use. Nitric acid (69\%, J.T. Baker, Deventer, Holland) and $\mathrm{H}_{2} \mathrm{O}_{2}$ (30\%, Merck,

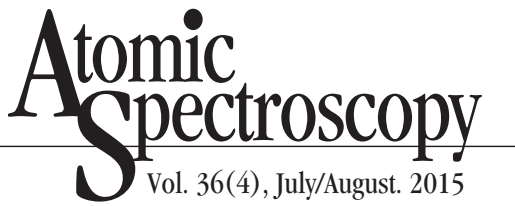

Darmstadt, Germany) were used for sample digestion.

Chemical modifier solutions containing $1000 \mathrm{mg} \mathrm{L}^{-1} \mathrm{Pd}\left(\mathrm{NO}_{3}\right)_{2}$ and $500 \mathrm{mg} \mathrm{L}^{-1} \mathrm{Mg}\left(\mathrm{NO}_{3}\right)_{2}$ were prepared by appropriate dilution of $10 \mathrm{~g} \mathrm{~L}^{-1}$ $\mathrm{Pd}\left(\mathrm{NO}_{3}\right)_{2}$ and dissolution of $\mathrm{Mg}\left(\mathrm{NO}_{3}\right)_{2} \cdot 6 \mathrm{H}_{2} \mathrm{O}$ (Suprapur ${ }^{\circledR}$, Merck, Darmstadt, Germany). These solutions were prepared in $0.05 \%(\mathrm{~m} / \mathrm{v})$ Triton ${ }^{\circledR} \mathrm{X}-100$ (Mallinckrodt Baker, Paris, KY, USA).

For DSS HR-CS GFAAS and ICPMS calibration, the $\mathrm{Pb}$ standard solutions were prepared by appropriate dilutions of the standard stock solution of $1000 \mathrm{mg} \mathrm{L}^{-1}$ (Spex Sample Preparation, Metuchen, NJ, USA).

The certified reference materials (CRMs) ERM-EC680 Trace Elements in Polyethylene (high level) and ERM-EC681 Trace Elements in Polyethylene (low level) from the Institute for Reference Materials and Measurements (Geel, Belgium) were cryogenically ground and used for method validation.

TABLE I

Operating Conditions of the ICP-MS Determinations

$\begin{array}{ll}\text { Instrumentation } & \text { PerkinElmer }{ }^{\circledR} \text { ELAN }{ }^{\circledR} \text { DRCTM II ICP-MS } \\ \text { Spray Chamber } & \text { Cyclonic } \\ \text { Nebulizer } & \text { Meinhard }{ }^{\circledR} \text { Model } \\ \text { RF power } & 1100 \mathrm{~W} \\ \text { Ar nebulizer gas flow } & 0.86-0.98 \mathrm{~L} \mathrm{~min}^{-1} \\ \text { Interface } & \text { Pt sampler } \\ \text { Sampling cone } & 1.1 \mathrm{~mm} \\ \text { Skimmer } & 0.9 \mathrm{~mm}\end{array}$

\begin{tabular}{ll} 
Measurement Parameters & \\
Scan mode & Peak hopping \\
Resolution & $0.7 \mu$ \\
Replicate time & $1 \mathrm{~s}$ \\
Dwell time & $50 \mathrm{~s}$ \\
Sweeps & 20 reading \\
Integration time & $1000 \mathrm{~ms}$ \\
Replicates & 3 \\
Isotopes & $208 \mathrm{~Pb}$ \\
\hline
\end{tabular}




\section{Sample Preparation}

Plastic materials for packaging food (white HDPE, white and brown PS) and for packaging beverage (green, yellow, red, and colorless PET) were chosen for analysis. These samples were ground using a cryogenic mill (Spex, model 6750 , USA). The grinding program consisted of a pre-cooling time of 4 minutes, followed by three cycles of 3-minute grinding with re-cooling intervals of 2 minutes.

Samples were also analyzed by ICP-MS after microwave-assisted acid digestion. For sample digestion, a mass of $150 \mathrm{mg}$ was accumicrowave PFA vessels, followed by the addition of $2.0 \mathrm{~mL}$ of concentrated nitric acid, $1.0 \mathrm{~mL}$ of hydrochloric acid, and $3.0 \mathrm{~mL}$ of deionized water. The mixture was submitted to the following heating program: (a) 0-800 W, 15 minutes ramp time; (b) $800 \mathrm{~W}, 40$ minutes hold; (c) $0 \mathrm{~W}$, and 20 minutes ventilation. The maximum temperature reached was $220^{\circ} \mathrm{C}$. The final digests were transferred to polypropylene flasks and diluted to $50-\mathrm{mL}$ volume with deionized water. rately weighed and transferred to

\section{RESULTS AND DISCUSSION}

\section{Method Development for the Determination of Lead}

Due to the high concentration of $\mathrm{Pb}$ in the CRMs ERM-EC680 and ERM-EC681 in relation to the samples, the proposed method optimization was carried out using a green PET sample. The concentration of $\mathrm{Pb}$ in this sample (81 $\left.\mathrm{g} \mathrm{kg}^{-1}\right)$ was previously determined by ICP-MS after sample digestion. The main $\mathrm{Pb}$ analytical line at $217.001 \mathrm{~nm}$ was used during all of the optimization experiments.

Initial experiments without a chemical modifier indicated that the pyrolysis curve exhibited thermal stability up to $700{ }^{\circ} \mathrm{C}$. However, double transient signals were observed during the atomization step fixed at $2000{ }^{\circ} \mathrm{C}$. In the present case, the double peak indicates the presence of two different forms of atomization mechanisms. In order to increase the thermal stability of the analyte and avoid double transient signals, pyrolysis and atomization curves were established using the chemical modifier $\mathrm{Pd}\left(\mathrm{NO}_{3}\right)_{2}+\mathrm{Mg}\left(\mathrm{NO}_{3}\right)_{2}$ in the presence of Triton ${ }^{\circledR} \mathrm{X}-100$. This strategy was previously used by Duarte et al. (14).

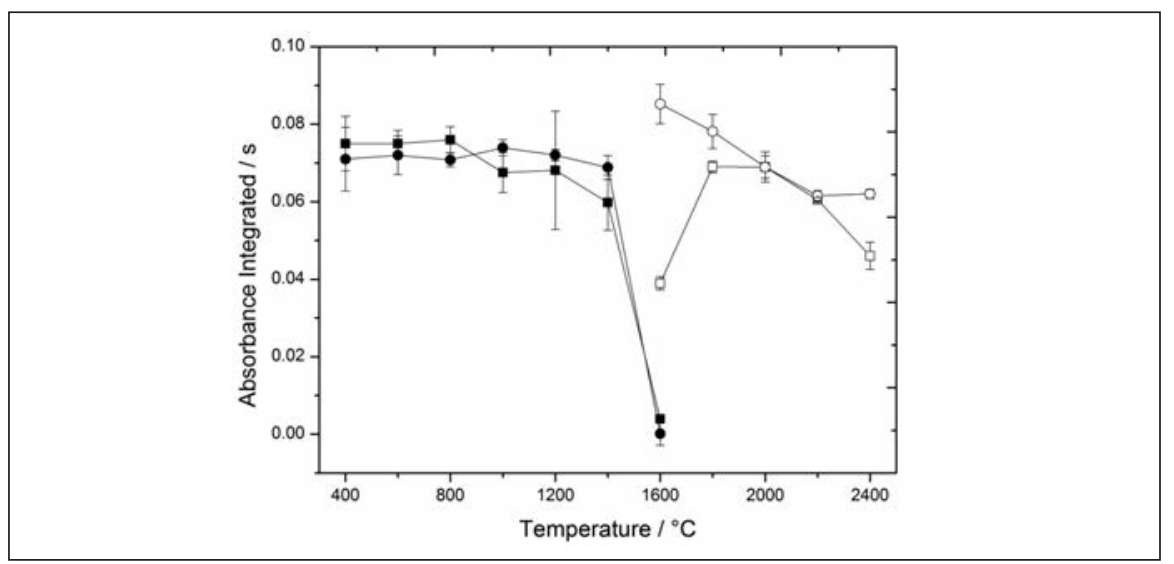

Fig. 1. Pyrolysis (using a $T_{a t}$ of $2000^{\circ} \mathrm{C}$ ) and atomization (using $a T_{p y r}$ of $1400{ }^{\circ} \mathrm{C}$ ) curves for Pb: (口) Integrated absorbance normalized to $0.6 \mathrm{mg}$ of the green PET sample, and (- $100 \mathrm{pg}$ of $\mathrm{Pb}$ in $10 \mu \mathrm{L}$ of aqueous standard solution.
To evaluate the effect of the modifier on the thermal stability of $\mathrm{Pb}, 5 \mu \mathrm{L}$ of a solution containing $5 \mu \mathrm{g}$ Pd and $2.5 \mu \mathrm{g} \mathrm{Mg}$ in $0.05 \%$ $(\mathrm{m} / \mathrm{v})$ Triton X-100 were dispensed over aliquots of analytical solutions and solid samples in the graphite platform. A mass of $0.6-0.8 \mathrm{mg}$ of the sample was used to evaluate the thermal behavior of $\mathrm{Pb}$ in the solid material. The effects of pyrolysis and atomization temperatures on $\mathrm{Pb}$ sensitivity in an aqueous standard solution and in the solid green PET sample using a chemical modifier are presented in Figure 1. A pyrolysis temperature of $1400{ }^{\circ} \mathrm{C}$ was adequate to eliminate the matrix. An atomization temperature of $2000{ }^{\circ} \mathrm{C}$ was chosen because it provided a single sharp peak for the atomic absorption signal, better precision, and fast return of the signal to the baseline. Also, at $2000{ }^{\circ} \mathrm{C}$ the analytical signal of $\mathrm{Pb}$ presented similar profiles for both media (Figure 2). The optimized temperature program used for the determination of $\mathrm{Pb}$ in plastic material for food beverage by DSS HR-CS GFAAS is presented in Table II. An additional pyrolysis step at $600{ }^{\circ} \mathrm{C}$ for $30 \mathrm{sec}$ onds assisted by air improved matrix removal.

Studies on minimum mass and homogeneity (15) were then conducted by analyzing different masses (0.05-1.0 mg) of sample with intervals of $0.1 \mathrm{mg}$. The most accurate and precise results were obtained for sample masses in the $0.6-0.8 \mathrm{mg}$ range. Therefore, $0.6-0.8 \mathrm{mg}$ of sample mass was used for all further investigations.

\section{Figures of Merit}

The limit of detection (LOD) and quantification (LOQ), the characteristic mass $\left(\mathrm{m}_{0}\right)$ and the correlation coefficient ( $r$ ) for the proposed method determined at $217.001 \mathrm{~nm}$ and $205.328 \mathrm{~nm}$ are presented in Table III. The LODs and LOQs were calculated as the concentration corresponding to 3 - and 10 -fold the 


\section{Atomic Apectroscopy \\ 1 Vol. 36(4), July/August. 2015}

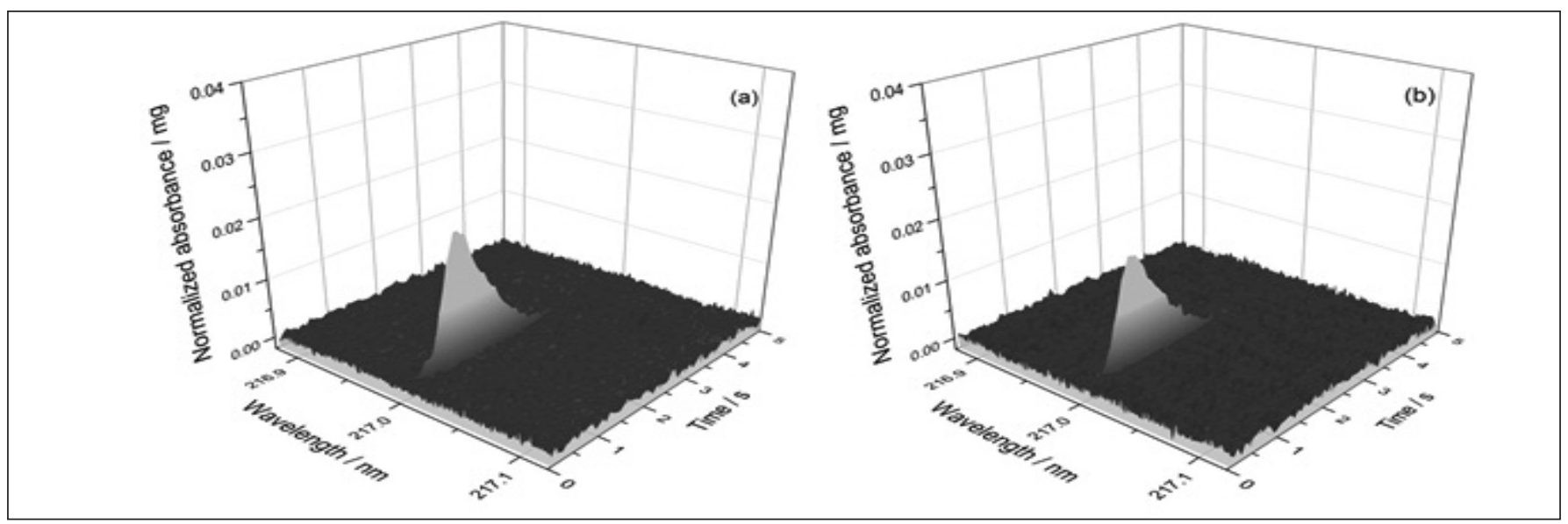

Fig. 2. Absorbance-time profile for Pb determination. Signals correspond to $100 \mathrm{pg} \mathrm{Pb}$ in $0.1 \%$ (v/v) $\mathrm{HNO}$ (a) and $\mathrm{Pb}$ in 0.6 mg of PET sample (b) using $5 \mu \mathrm{g}$ Pd and $2.5 \mu \mathrm{g} \mathrm{Mg}$ in $0.05 \%(\mathrm{~m} / \mathrm{v})$ Triton $\mathrm{X}-100$ as the modifier.

TABLE II

Optimized Heating Program for Lead Determination in Plastic Material Used for Food and Beverage Packaging by DSS HR-CS GFAAS

\begin{tabular}{lcccc}
\hline Step & $\begin{array}{c}\text { Temperature } \\
\left({ }^{\circ} \mathrm{C}\right)\end{array}$ & $\begin{array}{c}\text { Ramp } \\
\left({ }^{\circ} \mathrm{C} \mathrm{s}^{-1}\right)\end{array}$ & $\begin{array}{c}\text { Hold Time } \\
(\mathrm{s})\end{array}$ & $\begin{array}{c}\text { Argon Flow Rate } \\
\left(\mathrm{L} \mathrm{min}^{-1}\right)\end{array}$ \\
\hline Drying 1 & 110 & 10 & 10 & $2.0(\mathrm{Ar})$ \\
Drying 2 & 130 & 5 & 10 & $2.0(\mathrm{Ar})$ \\
Ash & 600 & 50 & 30 & $2.0(\mathrm{air})$ \\
Cooling & 100 & - & 20 & $2.0(\mathrm{Ar})$ \\
Pyrolysis & 1400 & 100 & 10 & $2.0(\mathrm{Ar})$ \\
Auto-zero & 1400 & 0 & 5 & 0 \\
Atomization & 2000 & 3000 & 4 & 0 \\
Cleaning & 2500 & 500 & 5 & $2.0(\mathrm{Ar})$ \\
\hline
\end{tabular}

standard deviation of the blank divided by the slope of the analytical curve (16). The standard deviation of the blank was calculated by repeatedly inserting an empty solid sampling platform containing only the modifier and running the temperature program (15). The characteristic mass $\left(\mathrm{m}_{0}\right)$ was obtained as the mass of analyte corresponding to an integrated absorbance of $0.0044 \mathrm{~s}$.

\section{Determination of Lead in Sam- ples and Certified Reference Materials}

The DSS HR-CS GFAAS method with calibration against aqueous standards was applied for the determination of $\mathrm{Pb}$ in 9 samples using the most sensitive analytical line at
$217.001 \mathrm{~nm}$. The concentration of $\mathrm{Pb}$ in the samples varied from 16 to $793 \mu \mathrm{g} \mathrm{kg}^{-1}$. In order to compare the results obtained by DSS HR-CS GFAAS, the samples were analyzed by ICP-MS after microwave-assisted acid digestion. All of the results are summarized in Table IV. A paired $t$-test at a $95 \%$ confidence level showed that the proposed method provided similar results as those obtained by ICP-MS. The precision, expressed as the relative standard deviation ( $R S D, n=3$ ), varied from 2.7 to $18.8 \%$ for the determinations by DSS HR-CS GFAAS and from 2.1 to $13.3 \%$ when using ICP-MS.

The proposed method for $\mathrm{Pb}$ determination was then applied for
TABLE III

Figures of Merit for Lead Determination in Plastic Material

Used for Food and Beverage Packaging by DSS HR-CS GFAAS

\begin{tabular}{lrr}
\hline Param- & \multicolumn{2}{c}{ Wavelength } \\
eters & $217.001 \mathrm{~nm}$ & $205.328 \mathrm{~nm}$ \\
\hline LOD* $^{*}$ & $4.9 \mu \mathrm{g} \mathrm{kg}^{-1}$ & $0.5 \mathrm{mg} \mathrm{kg}^{-1}$ \\
LOQ* $^{*}$ & $16 \mu \mathrm{g} \mathrm{kg}^{-1}$ & $1.65 \mathrm{mg} \mathrm{kg}^{-1}$ \\
$\mathrm{~m}_{\mathrm{o}}$ & $5.0 \mathrm{pg}$ & $0.4 \mathrm{ng}$ \\
$\mathrm{r}$ & 0.9998 & 0.9996 \\
\hline
\end{tabular}

* Calculated for $0.6 \mathrm{mg}$ sample.

two CRMs, and the results obtained are presented in Table V. Due to the high concentration of $\mathrm{Pb}$ in both CRMs, a less sensitive analytical line at $205.328 \mathrm{~nm}$ was used with the same temperature program developed for the most sensitive line. The proposed method provided accurate results based on an unpaired $t$-test at the $95 \%$ confidence level.

Duarte et al. (14) developed a method for the determination of $\mathrm{Pb}$ in plastic material from waste electric and electronic equipment using line source GFAAS and direct solid sampling analysis with deuterium background correction; the LOQ obtained was $72 \mu \mathrm{g} \mathrm{kg}^{-1}$. Obviously, the method with line source GFAAS 
TABLE IV

Results (mean \pm standard deviation, $\mu \mathrm{g} \mathrm{kg}^{-1}$ ) for Lead Determination $(n=3)$ in Plastic Material Used for Food and Beverage Packaging by the Proposed Method (DSS HR-CS GF AAS) and by the Comparative Technique (ICP-MS)

\begin{tabular}{lcc}
\hline Sample & DSS HR-CS GF AAS & ICP - MS \\
\hline Green PET & $82 \pm 8$ & $81 \pm 9$ \\
Blue PET & $27 \pm 4$ & $25 \pm 3$ \\
Red PET & $51 \pm 4$ & $54 \pm 4$ \\
Colorless PET & $44 \pm 4$ & $42 \pm 3$ \\
Brown PS & $793 \pm 51$ & $776 \pm 20$ \\
White PS & $735 \pm 20$ & $731 \pm 15$ \\
White HDPE 1 & $16 \pm 3$ & $17 \pm 2$ \\
White HDPE 2 & $24 \pm 4$ & $24 \pm 3$ \\
White HDPE 3 & $17 \pm 3$ & $15 \pm 2$ \\
\hline
\end{tabular}

(14) is not adequate to analyze the samples used in this study because the concentrations of $\mathrm{Pb}$ are below $72 \mu \mathrm{g} \mathrm{kg}^{-1}$ in $67 \%$ of the samples. However, the DSS HR-CS GFAAS method could perform this task because the LOQ obtained $\left(16 \mu \mathrm{g} \mathrm{kg}^{-1}\right)$ was 4.5 times lower than the line source GFAAS method.

\section{CONCLUSION}

The developed DSS HR-CS GFAAS method provided accurate results and adequate LOQ $\left(16 \mu \mathrm{kg}^{-1}\right)$ for the determination of $\mathrm{Pb}$ in plastic material used for food and beverage packaging by applying calibration against aqueous standards. That LOQ found is about 4.5 times lower than the LOQ described in a published work dealing with the determination of $\mathrm{Pb}$ in plastic material from waste electric and electronic equipment using line source GFAAS and direct solid sampling analysis with deuterium background correction. The proposed method is also characterized by a low consumption of reagents and minimum generation of laboratory residues in relation to ICP-MS detection after sample digestion.

\section{ACKNOWLEDGMENT}

The authors would like to thank the offer of grant No. 2014/ 12595-1 (São Paulo Research Foundation - FAPESP) and grant No. 471453/2013-7 (Conselho Nacional de Desenvolvimento Científico e Tecnológico (CNPq). The authors are also grateful to the Coordenação de Aperfeiçoamento de Pessoal de Nível Superior (CAPES) for fellowship to T.V.S., and the CNPq (grant 303255/2013-7) for researchship to J.A.G.N..

Received December 18, 2014.

\section{REFERENCES}

1. Plastics: A Global Outlook. Available at: <http://www.prweb.com/ releases/plastics_bioplastics/engin eered_plastics/prweb9194821.htm >. [Accessed 30 October 2014].

2. W. Romão, M.A.S. Spinacé and M. De Paoli, Polímeros 19, 121 ( 2009).

3. F. Welle, Resour. Conserv. Recy. 55, 865 (2011).

4. A. Janssen, B. Bruckner, and U. Kurfürst, Fresenius 322, 713 (1985).
TABLE V

Lead Concentration (mean \pm standard deviation, $\left.\mathrm{mg} \mathrm{kg}^{-1}\right)$ in Certified Reference Materials Determined $(n=3)$ by DSS HR-CS GF AAS

\begin{tabular}{lcc}
\hline CRM & \multicolumn{2}{c}{ Pb $\left(\mathrm{mg} \mathrm{kg}^{-1}\right)$} \\
& Certified & Determined \\
\hline ERM- & & \\
EC680 & $107.6 \pm 2.8$ & $98.6 \pm 6.3$ \\
ERM- & & \\
EC681 & $13.8 \pm 0.7$ & $12.2 \pm 2.8$ \\
\hline
\end{tabular}

5. M.A. Belarra, M. Resano, S. Rodríguez, J. Urchaga and J.R. Castillo, Spectrochim. Acta B 54, 787 (1999).

6. M.A. Belarra, I. Belategui, I. Lavilla, J.M. Anzano and J.R. Castillo, Talanta 46, 1265 (1998).

7. M. Resano, M. Aramendía, E. GarcíaRuiz, C. Crespo and M.A. Belarra, Anal. Chim. Acta 571, 142 (2006).

8. M. Resano, J. Briceno and M.A. Belarra, Spectrochim. Acta B 64, 520 (2009).

9. S. Cadore, E. Matoso and M.C. Santos, Quím. Nova 31, 1533 (2008).

10. S. Waheed, N. Siddique, S. Rahman and S.M. Husnain, J. Radioanal. Nucl. Chem. 292, 937 (2011).

11. J.S.F. Pereira, C.L. Knorr, L.S.F. Pereira, D.P. Moraes, J.N.G. Paniz, E.M.M. Flores and G. Knapp, J. Anal At. Spectrom. 26, 1849 (2011).

12. R. Lemaire, D. Del Bianco, L. Garnier and J. L. Beltramo, Anal. Lett. 46, 2265 (2013).

13. I.N.B. Castilho, E.R. Pereira, B. Welz, A.A. Shaltout, E. Carasek and I.B. Gonzaga Martens, Anal. Methods 6, 2870 (2014).

14. A.T. Duarte, M.B. Dessuy, M.M. Silva, M.G.R. Vale and B. Welz, Microchem. J. 96, 102 (2010).

15. U. Kurfürst, Solid Sample Analysis, Springer, Berlin, Germany (1998).

16. A. Gustavo González and M. Angeles Herrador, Trends Anal. Chem. 26, 227 (2007). 